\title{
A METHODOLOGICAL FRAMEWORK FOR MEASURING THE LEVEL OF CONVENIENCE OF TRANSPORT TICKETING SYSTEMS
}

\author{
Dušan ZALAR ${ }^{1^{*}}$, Rasa UŠPALYTĖ-VITKŪNIENE ${ }^{2}$, Danijel REBOLJ ${ }^{3}$, Marjan LEP ${ }^{4}$ \\ ${ }^{1}$ Directorate for Transport, Ministry for Infrastructure, Ljubljana, Slovenia \\ ${ }^{2}$ Dept of Urban Engineering, Vilnius Gediminas Technical University, Vilnius, Lithuania \\ ${ }^{3,4}$ Faculty of Civil Engineering, Transportation Engineering and Architecture; \\ University of Maribor, Maribor, Slovenia
}

Received 21 April 2016; revised 13 October 2016; accepted date 4 February 2017; published online 3 May 2017

\begin{abstract}
Public transport sustainability is becoming a major driver for public transport development. Public transport ridership represents one of the key performance indicators of sustainability in the sense of balancing the economic, social and environmental aspects of public transport. There are various methods for improving the attractiveness of public transport for passengers by reducing resistances, which discourage potential and existing passengers to use public transport. Transport ticketing is one of the methods. This article presents a methodological framework for evaluating transport ticketing technologies with the use of a transport ticketing convenience model developed by the authors as well as some survey results through the application of the developed framework on traditional smart ticketing and contactless payment card ticketing technologies. First, a methodological framework for modelling ticketing convenience based on end-to-end passenger experience is presented. Second, a ticketing convenience model for barrier-free and double-sided validation baseline ticketing systems is developed. Third, the ticketing system based on contactless bank payment cards is compared with traditional smart ticketing systems in terms of convenience. It is shown that a contactless payment cards ticketing system has greater convenience or a better, more seamless travel experience than traditional smart systems. Finally, some research perspectives on enhancing the ticketing convenience model by using mobile smartphones with NFC, BLE and GPS technology, as well as the inclusion of technologies related to ticketing such as passenger information systems into the model, are contemplated.
\end{abstract}

Keywords: public transport, passenger experience, travel convenience, transport ticketing, transport ticketing convenience, contactless payment cards, contactless bank cards.

\section{Notations}

BLE - Bluetooth Low Energy;

CPC - Contactless Payment Cards;

GPS - Global Positioning System;

IDT - Innovation Diffusion Theory;

MCDM - Multi-Criteria Decision-Making;

NFC - Near Field Communication;

PayG - Pay as you Go;

PayB - Pay Before;

SAW - Simple Additive Weighting;

SMS - Short Message Service;

TAM - Technology Acceptance Model;

UE - Usability Engineering;

WSM - Weighted Sum Method.

\section{Introduction}

Ridership is one of the key performance indicators of public transport sustainability in the sense of balancing the economic, social and environmental aspects of public transport. To attract new and retain existing passengers, public transport agencies devote a lot of attention to travel time, fare price, travel convenience and other qualitative factors. Travel convenience cannot be measured like travel time or fare price. Travel convenience is an ambiguous concept, often showing a high degree of overlap with other service attributes (Crockett, Hounsell 2005). Travel convenience can be related to all stages of the journey, from initial planning to arrival at the destination. There is no universal definition of which service attributes come under the definition of convenience (Anderson et al. 2013). Berry et al. (2002) conceptualise

${ }^{*}$ Corresponding author. E-mail: dusan.zalar@gmail.com 
service convenience as consumers' time and effort perceptions related to buying or using a service (easy to buy or use) and propose five dimensions of convenience: decision, access, transaction, benefit, and post benefit. These dimensions reflect stages of consumers' activities related to buying or using a service. Inconvenience is an opposite concept and means lack of convenience. The definition of inconvenience is even more indeterminate. The Oxford English Dictionary (2016) defines inconvenience as: 'the state or fact of being troublesome or difficult with regard to one's personal requirements or comfort'. In many circumstances, consumers make judgements of 'inconvenience' rather than judgements of 'convenience. Understanding of inconvenience has considerable potential as a basis for improvement of the service. Inconvenience is a multidimensional construct, although there is no agreement on what these dimensions are nor on whether the dimensions of inconvenience are consistent with those of convenience (Farquhar, Rowley 2009). Convenience is an aspect of the consumer experience. The concept of customer experience was first introduced by Pine and Gilmore (1998) and later by Ferreira and Teixeira (2013). Travel convenience may seem to be relatively unimportant, but still it can influence the decision to travel (Annema 2013). Various components contribute to travel convenience. One of them is the transport ticketing system. With the emergence of new technologies such as multi-application smart cards, account-based ticketing and the application of payment cards as transport tickets, and NFC- and BLE-enabled smart mobile phones, transport ticketing is becoming more and more important as a tool to attract new passengers.

There are several studies on how transport ticketing technologies can benefit public transport. Depending on the technology used and its implementation, benefits can be had by both passengers and operators as well as transport agencies. Cashless service (Graham, Mulley 2012), fast validation times (Tirachini 2013) and flexible fare management are the main features of smart ticketing which affect public transport. Integrated ticketing, as one of the options of flexible fare management, has been on the agenda of EU transport policy for over a decade (Puhe et al. 2014). Integrated ticketing is expected to deliver greater flexibility and convenience for passengers, thus prompting greater use of public transport (Turner, Wilson 2010). Convenient ticketing was used in a coordinated package of mutually supportive policies to increase ridership in Germany with proven success (Buehler, Pucher 2012). That a public transport service needs to offer appropriate ticketing in order to be easy to use was also recognised by the International Transport Forum (Anderson et al. 2013). One of the main issues in the field of transport ticketing is the ability to evaluate the impact of different types of transport ticketing systems on ridership in order to support the decision to introduce, upgrade or replace the transport ticketing system.

There are also some published inconveniences for transport ticketing technologies. With the recent intro- duction of contactless payments on traditional smart ticketing systems in London, the most well known inconvenience is card clash (TfL 2016). Card clash is a situation when two or more contactless smart cards interfere with each other, e.g. Oyster and MasterCard (TfL 2016). The result of card clash is double charging or charging a fare on a card a passenger did not intend to pay with.

Various discrete choice models are generally used for ridership forecasting. The commonly used modal choice model includes mode characteristic attributes (travel time, travel cost, ...), socio-economic characteristic attributes (gender, age, employment, income, car, children, ...) and travel characteristic attributes (frequency, distance, purpose, ...) while omitting personal attitudes and perceptions (convenience, comfort, security, ...). Attitudes and perceptions (convenience is a perception) are latent variables. A general methodology and framework for including latent variables (in particular, attitudes and perceptions) in choice models was developed by Ben-Akiva et al. (1999). Integration of latent variables and the choice model can be simultaneous or sequential (two-step). In any case, a latent variable model is required. Thus, to assess the impact of convenience of the transport ticketing on travel demand, a model for ticketing convenience is required.

Besides the construct of convenience, which has roots in the field of marketing, there also exist other approaches to predict the user intentions of using a specific product or service, especially from the field of information technology. The most common approaches are the TAM, IDT and UE. The TAM developed by Davis (1989) predicts that user acceptance of any technology is determined by two factors: perceived ease of use and perceived usefulness. In the third revision of the model, these two factors are anchored and influenced by several determinants (Venkatesh, Bala 2008). IDT determines five innovation characteristics which affect the adoption of the innovation: relative advantage, complexity, compatibility, trialability, and observability (Rogers 1995). The ISO 9241-11:1998 defines usability as: 'the extent to which a product can be used by specified users to achieve specified goals, with effectiveness, efficiency and satisfaction, in a specified context of use'. Nielsen's (1993) definition of usability includes, in addition to efficiency in normal use and satisfaction with use: learnability in early use, memorability after a period of non-use, and error correction (protection) during use. Currently, a revision of the standard is being undertaken. The new draft includes learnability and error protection (Bevan et al. 2015).

All these theories seem to exist independently of each other, although there is some overlapping, similarity and complementarity between them. In practice, different approaches are used to support the decision to introduce a new ticketing system. Some of them are stated below.

The stated preference survey and discrete choice modelling approach was used to assess the level of ridership demand for different future fare-medium options 
(TfL card - similar to an Oyster card, contactless payment card or paper ticket) among different ridership groups at Transport for London and the Chicago Transit Authority (payment card or current fare media - Chicago card is one of available options). The survey is limited to pay-as-you-go ticketing systems with double-ended validation. The results showed that approximately 33\% of riders in London and 36\% of riders in Chicago prefer payment cards. A description of the alternatives (functionality of the ticketing systems) in the survey is incomplete and leaves significant room for improvements (Brakewood, Kocur 2011). Besides socioeconomic and travel characteristics, both models also include financial characteristics which are slightly different between the two models (London: banked; Chicago: banked, frequency of cash payments, awareness of contactless bankcards). Both used choice models predict the adoption of new ticketing systems among existing passengers and not the shift in the modal choice (increased or decreased ridership). In addition, the ticketing characteristics represented as a single attribute (ticket type) is much too simplified for the comparison of modern, sophisticated ticketing systems regarding ridership.

The same approach was used to forecast adoption of mobile ticketing (mobile ticketing, existing fare media) on commuter rail lines in the greater Boston area. The study is limited to prepaid single-ride tickets in the form of a barcode, which has to be activated before the ride. The ticket and barcode can be displayed on mobile phones. The barcode is used for single-ended validation done by the conductor or for ticket inspection done by controllers. The results showed that approximately $26 \%$ of rail riders are likely to adopt mobile ticketing (Brakewood et al. 2014).

A usability analysis was used to improve (upgrade) the OV-Chipkaart ticketing system. The analysis includes comparison of three ticketing systems: OVChipkaart (Netherlands), Oyster (London) and Octopus (Hong Kong). To analyse different aspects of travelling and to identify problem areas, the customer journey is divided into four main phases: purchase, pre-travel, travel and post-travel experiences, which were further divided into 11 steps. The usability comparison of ticketing systems in the study is qualitative in sense of positive and negative aspects of the ticketing system regarding each journey phase. The comparison was based on the customer journey map. Customer journey mapping is a tool to help both design and assess the customer experience (Johnston, Kong 2011). The study highlights a lot of possibilities for improvements to the ticketing systems by identifying usability problems (Joppien et al. 2013). The study uses the ISO 9241-11:1998 definition of usability.

The TAM in conjunction with the diffusion of innovations concept was used by the Helsinki Public Transport to investigate mobile ticketing adoption. The study is limited to prepaid single-ride tickets in the form of SMSs. A flat fare SMS ticket is valid for a period of time on different transport modes. SMS tickets are ordered by SMS to a premium number and billed through mobile network operators. The study analyses key determinants of technology adoption from a TAM and diffusion of innovations concept along with some factors based on findings in the field of mobile commerce and consumer behaviour. The results showed that the strongest determinant for use intention was prior experience and not ease of use or usefulness (Mallat et al. 2008).

While UE is oriented towards the relationship between service provider and service, convenience modelling is oriented towards the relationship between service consumer and service. As none of the previous studies went in depth on the convenience of the actual systems, the convenience model approach seems to be somewhat neglected for no apparent reason.

Despite a relatively large number of studies about the different impacts of transport ticketing technologies on public transport, the authors see a lack of knowledge of transport ticketing technologies' impacts on ridership. The question of which ticketing technology has the bigger impact on ridership or how to evaluate the impact of ticketing technology on ridership still remains open. Travel convenience, especially related to transport ticketing and related technologies, is poorly defined. Because new emerging ticketing technologies are becoming mature enough to deploy at least with limited functionality and extent, we need advanced ridership forecasting models. The convenience model could help provide more accurate ridership forecasts.

The objective of this article is to suggest a methodological framework for measuring the convenience of transport ticketing (regardless of used technology), and to demonstrate the use of this framework to help policymakers (public transport authorities and public transport operators) when introducing, upgrading or replacing ticketing systems. In order to achieve this objective, the end-to-end passenger experience approach will be used to develop the transport ticketing convenience model, which could further be used in ridership forecasting methods such as modal split based on hybrid discrete choice models.

\section{Methods}

According to the 'experience economy' concept, the authors conceptualised the end-to-end passenger experience as a number of interactions (touch points) between the passenger and the public transport operator's ticketing system. The authors defined the convenience of a public transport ticketing system (transport ticketing convenience) as 'a set of conveniences (convenience factors) according to interactions (touch points) between the passenger and transport ticketing system. To quantify the convenience of a ticketing system the authors chose a multi-criteria decision making method, where a set of alternatives represents ticketing systems, criteria journey phases and sub-criteria convenience factors (touch points). Three steps are characteristic for any MCDM method: determining the relevant criteria, attaching numerical measures to the relative importance of the criteria (weights) and to the impacts of the alternatives on these criteria, and determining the 
overall performance of alternatives (Triantaphyllou et al. 1998). The authors propose a four-step methodological framework for measuring the convenience of transport ticketing:

- step 1: decomposition of passenger journey;

- step 2: identification of convenience factors;

- step 3: convenience model generation;

- step 4: convenience evaluation.

When using an MCDM, the purpose of the first and the second step is to identify and structure the relevant criteria. The purpose of the third step is to weight the criteria and generate a model of the overall performance of the alternatives. The purpose of the forth step is to measure the performance of the alternatives on identified criteria and calculate the overall performance of the alternatives. The proposed methodological framework addresses the method to identify and structure transport ticketing convenience factors (step 1 and 2) as well as the method to measure the convenience of different transport ticketing systems on these factors (step 4).

\subsection{Decomposition of passenger journey}

To analyse the convenience of any transport ticketing system regardless of its technology and functionality (i.e. regardless of the number and type of the touch points), the authors decomposed the passenger journey into six journey phases, which cover the end-to-end passenger experience. The authors called the journey phases the information phase, the planning phase, the booking phase, and the pre-ride, in-ride and post-ride phases (Figure 1). The pre-ride, in-ride and post-ride phases represent door-to-door travel.

This decomposition of the passenger journey is slightly different than the one used in the usability analysis of OV-Chipkaart (Joppien 2013; Joppien et al. 2013). The authors' opinion is that the meaning of the purchase phase in the usability analysis is very narrow and in some way limited to smart ticketing. The authors propose three journey phases with a broader meaning (information, planning and booking) to be able to analyse mobile ticketing with passenger information, booking and navigation capabilities.

In addition, the decomposition in the usability analysis is partially dependent on technology. For example, the travel experience phase includes the possibility to transfer from one means of transport to another (interchange) without check-in and/or check-out. In general, the journey may be composed of several rides using different transport modes. The authors propose that in that case, the journey phases pre-ride, in-ride and post-ride are repeated for each ride. In the case of integrated ticketing systems or one-stop ticketing offices, the information, planning and booking phases may be common for all rides within the integration.

\subsection{Identification of Convenience Factors}

Ticketing systems usually support several ticket types in order to satisfy the needs of different groups of passengers and for different travel purposes. For example, season tickets are devoted to regular passengers, while single tickets are devoted to occasional passengers. Stored-value tickets are usually devoted to frequent passengers in urban areas. The authors propose analyses of use-case scenarios based on different ticket types and their features to identify interactions (touch points) between the passenger and ticketing system and to align them across previously defined journey phases. In this case, the journey phases of the ticketing system are represented as clusters of interactions (touch points) used in scenarios. Identified interactions (touch points) represent transport ticketing convenience factors.

Some ticketing systems may have more touch points than others as well as different touch points. For example, single-ended validation ticketing systems have a check-in touch point, while double-ended validation systems have check-in and check-out touch points. In addition, some ticketing systems may have logically equal touch points, but executed in different time sequences. For example, gated ticketing systems have check-in touch points before boarding, while ungated ticketing systems have check-in touch points at boarding. Furthermore, different ticket types in the same system may have different touch points. For example, in order to be reused, stored-value tickets must be topped up, while season tickets must be renewed.

To highlight these touch point scenarios, the authors proposed a customer journey mapping method to visualise scenarios throughout an existing service (Figure 2). First, all ticket types for the existing service should be identified. Next, one or more use-case scenarios for each ticket type should be constructed. Touch points have to be detected for each scenario. The scenarios can be quite complex; they must cover all possible (interactions) touch points for the associated ticket type. Each touch point (white circle in Figure 2) for a given scenario will receive weight for use in the next step in the framework.

\subsection{Convenience model generation}

There are many MCDMs to determine the overall performance value of alternatives (Velasquez, Hester 2013). It is beyond the scope of this article to analyse the appropriateness of specific methods for determining the overall convenience of the ticketing system. The authors propose a WSM, also known as SAW, as the simplest method. In this case, the overall convenience of a ticketing system is defined as a weighted sum of convenience

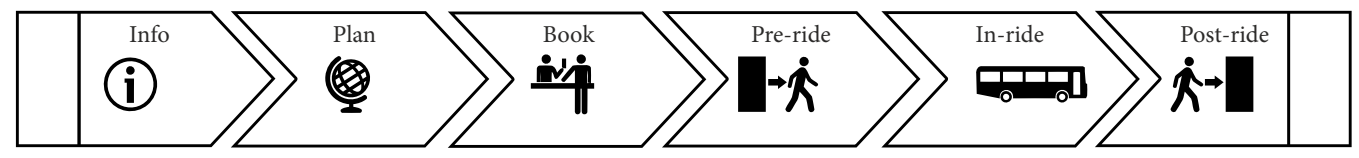

Figure 1. End-to-end passenger experience and the six journey phases 


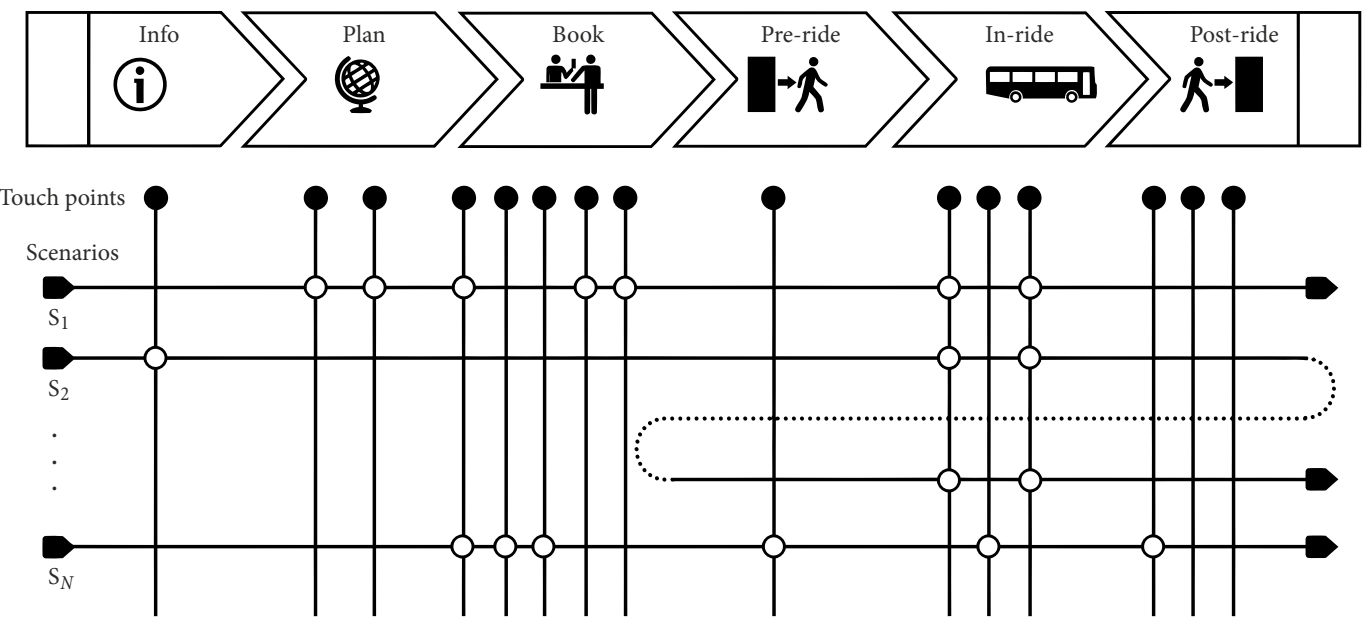

Figure 2. Identification of touch points through use-case scenarios

factors. Thus, convenience $c_{x}$ for any ticketing system $x$ can be expressed in general as:

$$
c_{x}=\sum_{i=1}^{N} \sum_{j=1}^{M(i)} w_{(i)(j)} \cdot c_{x(i)(j)},
$$

where: $w_{(i)(j)}$ represents the normalised weight of the convenience factor; $c_{x(i)(j)}$ the convenience factor for touch point $j$ within journey phase $i ; M_{(i)}$ represents the number of touch points within journey phase $i$; $N$ number of journey phases.

The authors believe that it is easier to weight a smaller number of criteria, so they propose hierarchical weighting (i.e. weighting of journey phases and convenience factors within journey phases). Weights of convenience factors are rescaled regarding the number of convenience factors within the journey phase in order to exclude the impact of variation of the number of convenience factors within each journey phase and are expressed as:

$$
\begin{aligned}
& w_{(i)(j)}=w_{(i)} \cdot w_{(i, j)} \cdot R_{(i)} ; \\
& R_{(i)}=\frac{M_{(i)}}{\sum_{k=1}^{N} M_{(k)}}
\end{aligned}
$$

where: $w_{(i)}$ is the normalised weight of journey phase $i$; $w_{(i, j)}$ is the normalised weight of convenience factor $j$ within journey phase $i ; R_{(i)}$ is the rescaling factor.

Different weighting methods have been developed for use in different MCDMs (Zardari et al. 2015). The authors propose regular ranking (five-grade discrete linear scale) for weighting journey phases and touch points as it is simple and allows equal importance:

$$
\begin{aligned}
& w_{(i)}=\frac{r_{(i)}}{\sum_{k=1}^{N} r_{(k)}} ; \\
& w_{(i, j)}=\frac{r_{(i, j)}}{\sum_{k=1}^{M_{(i)}} r_{(i, k)}} .
\end{aligned}
$$

\subsection{Convenience evaluation}

Understanding the usage of new innovative ticketing systems is crucial to their evaluation. The description of possible ticket types and their many features is often difficult to understand even to an expert, not to mention ordinary travellers. The authors believe that the description of ticketing systems through use-case scenarios is a good practice not only to identify the touch points but also to explain to the evaluators (experts and ordinary travellers) how to use the new, innovative ticketing system. Furthermore, several simple scenarios with few touch points are easier to understand and evaluate than one complex scenario. According to these beliefs, the authors propose a structured questionnaire based on usecase scenarios for different ticket types for quantification of the convenience of touch points. For each ticket type, several simple scenarios should be constructed in order to cover all possible touch points for that ticket type.

The absolute performance of convenience is needed for ridership forecasting. Thus, the result of the quantification method must be convenience magnitude. A convenience absolute score scale needs to be constructed for quantification. The authors are aware that absolute scoring is very difficult. To ease this difficulty, they suggest the simultaneous scoring of each touch point for all ticketing systems, which are subject to the measurement.

According to the definition of convenience (consumers' time and effort perceptions), the convenience scoring scale has three dimensions: mental effort, physical effort and time consumed. The authors suggest a five-grade discrete linear scale to score the level of convenience of each convenience factor (Table 1).

\subsection{The survey}

The purpose of the survey was to demonstrate the use of the framework. The survey compares transport ticketing systems based on contactless payment cards (as one of the most advanced systems) with traditional smart ticketing systems (as one of the most common) in terms of convenience. 
Table 1. Convenience scoring scale

\begin{tabular}{|l|l|c|c|}
\hline \multicolumn{1}{|c|}{ Level of convenience } & \multicolumn{1}{|c|}{ Description of activity requirements (mental effort, physical effort and time consumed) } & Score \\
\hline Very high & very little concentration; negligible amount of time and trivial physical activity & 5 \\
\hline High & very little concentration; considerable amount of time or non-trivial physical activity & 4 \\
\hline Medium & moderate concentration; negligible amount of time and trivial physical activity & 3 \\
\hline Low & moderate concentration; considerable amount of time or non-trivial physical activity & 2 \\
\hline Very low & extensive concentration; regardless of required time and physical activity & 1 \\
\hline
\end{tabular}

Traditional smart ticketing utilises smart cards with stored tickets or monetary value. Ticket validation is done exclusively with the smart card and validator (Smart Card Alliance 2011).

Like traditional ticketing systems, CPC ticketing systems have PayG and PayB travel capabilities. The Contactless Transit Framework describes how a customer could travel on public transport using a contactless payment card (or device such as a phone or wearable) which has been issued by their bank or card company. The Framework includes three Contactless Transit Models: Single PayG, Aggregated PayG and Pre-Purchase. The Single PayG cash replacement model is used to pay a known fare at the start of the journey (check-in only). The Aggregated PayG cash replacement model is used to pay variable fares at the end of a ride (check-in and check-out) and can aggregate several payments into one charge. Price capping on aggregation is also possible. The Pre-Purchase paper ticket replacement model uses a contactless card or device that is associated with the ticket in advance and then used as a form of identity to travel (The UK Cards Association Ltd 2015). These models support the possibility of emulating stored-value tickets, single- or multiple-ride tickets and season tickets. However, unlike the integration concept for traditional systems, an interoperability concept is used for the contactless bank payment cards system (at least for now). It is not possible to implement PayG travel where the single-ride price is higher than the contactless limit. Contactless payment cards are designed for small value payments. In urban public transportation, single-ride ticket prices are usually below the contactless limit, while in interurban (long distance) travel they are above the contactless limit. Pay-before travel is very convenient for purchasing a ticket and seat reservation where vehicle capacity is limited like airline and highspeed train tickets. Prepaid contactless bank cards may be used for underbanked and unbanked people (Smart Card Alliance 2008, 2011; Brakewood 2010).

The question of whether and how the CPC ticketing system can functionally replace the traditional system entirely as well as whether there is a business case for replacement is beyond the scope of this article. Replace entirely means that the ticketing system only accepts CPCs, all transactions are cashless, all ticket types have equivalents and all groups of passengers have equivalent opportunities compared with traditional ticketing systems.
Besides CPC ticketing, mobile ticketing seems to be the most promising option to improve the passenger experience. Mobile ticketing has many different technology options. Smart phones can be used directly as tickets in at least two ways: by NFC card emulation and by 2D barcode display. NFC card emulation can emulate either contactless transport or contactless payment cards.

The survey has two parts. The purpose of the first part was the generation of a transport ticketing convenience model and the purpose of the second part was the measurement of the convenience of two transport ticketing systems. The model generation was based on the framework and the Delphi method was used to collect the data.

The survey should support the decision to introduce a CPC ticketing system.

\subsubsection{Generation of the convenience model}

The six journey phases determined in the methodological framework (step 1: decomposition of passenger journey) were used to decompose the journey.

It was assumed that the ticketing system, based on the three most common ticket types - stored-value tickets, single- or multiple-ride tickets and season tickets is a good baseline to analyse the convenience of ticketing technologies.

For the case studies, the existing ticketing systems of Slovenia and Lithuania were chosen. E-ticketing in Lithuanian cities was implemented recently and an analysis of the travel convenience changes could be done. Additionally, problems faced in the systems can already be seen. Slovenia was chosen because a public transport integration project is now in the implementation phase. One of the project's objectives is to increase ridership with the introduction of a country-wide single ticket.

Use-case scenarios for regular passengers using season tickets, occasional passengers using single tickets and frequent passengers using stored-value tickets were analysed for traditional, CPC and mobile ticketing systems. The existing ticketing systems of:

- Urbana (Ljubljana, Slovenia) - http://www.jhl.si/ enotna-mestna-kartica-urbana;

- mobile Urbana (Ljubljana, Slovenia) - http:// www.jhl.si/enotna-mestna-kartica-urbana/mobilna-aplikacija-urbana/uporaba-aplikacije;

- e-Ticket (Vilnius, Kaunas and Klaipeda, Lithuania) - http://www.vpo.lt/en/electronic-ticket\#;

- m.Ticket (Vilnius, Lithuania) - http://itero.lt; 
- OV-Chipkaart (Netherlands) - https://www.ovchipkaart.nl/home.htm;

- Oyster (London, UK) - https://oyster.tfl.gov.uk/ oyster/entry.do;

- contactless TfL (London, UK) - https://contactless.tfl.gov.uk;

and the capabilities of the Contactless Transit Framework (The UK Cards Association Ltd) were considered in the analysis. Urbana and e-Ticket present local urban ticketing systems, while Oyster presents one of the most advanced urban ticketing systems. OV-Chipkaart is the first nationwide interoperable fare collection system and the Contactless Transit Framework presents the most advanced CPC ticketing option. Mobile Urbana is NFC-based, while mTicket is based on 2D barcodes. The relevant convenience factors identified according to the methodological framework (step 2: identification of convenience factors) are presented in Table 2.

According to the relevant convenience factors in Table 2 , the overall convenience $c_{x}$ for any ticketing system $x$ can be expressed in general as (step 3: convenience model generation):

$$
\begin{aligned}
& c_{x}=w_{(\text {info })(\text { general })} \cdot c_{x(\text { info })(\text { general })}+ \\
& w_{(\text {plan })(\text { ticket })} \cdot c_{x(\text { plan })(\text { ticket })}+ \\
& w_{(\text {plan })(\text { invoice })} \cdot c_{x(\text { plan })(\text { invoice })}+ \\
& w_{(\text {book })(\text { media })} \cdot c_{x(\text { book })(\text { media })}+ \\
& w_{(\text {book })(\text { new })} \cdot c_{x(\text { book })(\text { new })}+ \\
& w_{(\text {book })(\text { renew })} \cdot c_{x(\text { book })(\text { renew })}+ \\
& w_{(\text {book })(\text { topup })} \cdot c_{x(\text { book })(\text { topup })}+
\end{aligned}
$$

$$
\begin{aligned}
& w_{(\text {book })(\text { invoice })} \cdot c_{x(\text { book })(\text { invoice })}+ \\
& w_{(\text {pre })(\text { cin })} \cdot c_{x(\text { pre })(\text { cin })}+ \\
& w_{(\text {ride })(\text { cin })} \cdot c_{x(\text { ride })(\text { cin })}+ \\
& w_{(\text {ride })(\text { inspect })} \cdot c_{x(\text { ride })(\text { inspect })}+ \\
& w_{(\text {ride })(\text { cout })} \cdot c_{x(\text { ride })(\text { cout })}+ \\
& w_{(\text {post })(\text { cout })} \cdot c_{x(\text { post })(\text { cout })}+ \\
& w_{(\text {post })(\text { cancel })} \cdot c_{x(\text { post })(\text { cancel })}+ \\
& w_{(\text {post })(\text { balance })} \cdot c_{x(\text { post })(\text { balance })} .
\end{aligned}
$$

The Delphi method was used to rank the journey phases and touch points in terms of importance. It was conducted by an expert group of 18 members with research experience in public transport from two different research organisations. The number of iterations was limited to two rounds. The Delphi method is a widely

\begin{tabular}{|c|c|c|c|c|}
\hline \multicolumn{3}{|c|}{ Journey phases } & \multicolumn{2}{|r|}{ Convenience factors (touch points) } \\
\hline & $\begin{array}{l}\text { information } \\
\text { phase }\end{array}$ & info & general & $\begin{array}{l}\text { ticketing media, ticket types (features) and price information (interaction with } \\
\text { passenger information system) }\end{array}$ \\
\hline \multirow[b]{2}{*}{8} & \multirow{2}{*}{$\begin{array}{l}\text { planning } \\
\text { phase }\end{array}$} & \multirow[b]{2}{*}{ plan } & ticket & ticket type selection \\
\hline & & & invoice & $\begin{array}{l}\text { proforma invoice delivery (interaction with journey planner - passenger } \\
\text { information system) }\end{array}$ \\
\hline \multirow{5}{*}{ vil } & \multirow{5}{*}{$\begin{array}{l}\text { booking } \\
\text { phase }\end{array}$} & \multirow{5}{*}{ book } & media & ticketing media order, payment and delivery (interaction with payment system) \\
\hline & & & new & $\begin{array}{l}\text { new ticket order (seat reservation), payment and delivery (interaction with } \\
\text { booking and payment system) }\end{array}$ \\
\hline & & & renew & ticket renewal order, payment and delivery (interaction with payment system) \\
\hline & & & topup & ticket top-up order, payment and delivery (interaction with payment system) \\
\hline & & & invoice & invoice - receipt delivery \\
\hline & $\begin{array}{l}\text { pre-ride } \\
\text { phase }\end{array}$ & pre & $\operatorname{cin}$ & ticket validation at enter (at gates) \\
\hline \multirow{3}{*}{ ل } & \multirow{3}{*}{ in-ride phase } & \multirow{3}{*}{ ride } & $\operatorname{cin}$ & ticket validation at enter (on board) \\
\hline & & & inspect & ticket and identity inspection \\
\hline & & & cout & ticket validation at exit (on board) \\
\hline \multirow{3}{*}{$\dot{\mathcal{K}} \rightarrow$} & \multirow{3}{*}{$\begin{array}{l}\text { post-ride } \\
\text { phase }\end{array}$} & \multirow{3}{*}{ post } & cout & ticket validation at exit (at gates) \\
\hline & & & cancel & return and refund media, refund unused or cancelled tickets \\
\hline & & & balance & return and refund media, refund unused stored value \\
\hline
\end{tabular}
used and accepted method to achieve a convergence of opinion on a specific issue (Hsu, Sandford 2007).

\subsubsection{Convenience evaluation}

For scoring the convenience of touch points, a two-column tabular questionnaire was composed. One column has been devoted to the scenario of a traditional ticketing system and one column to the scenario of a CPC ticketing system. Each row in the table has been devoted to a single touch point. A sample touch point for scoring the convenience is presented in Figure 3. The described structure of the questionnaire thus enables the simultaneous scoring of each convenience factor for both ticketing systems (step 4: convenience evaluation).

Table 2. Public transport ticketing system convenience factors (touch points) 


\begin{tabular}{|c|c|c|c|}
\hline & Traditional smart system & \multicolumn{2}{|l|}{ CPC system } \\
\hline \multirow[t]{3}{*}{ 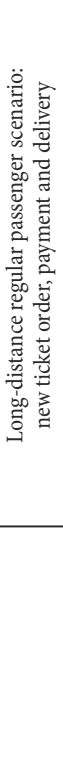 } & $\begin{array}{l}\text { You already have a personalised transport card } \\
\text { which is accepted by your local transport network. } \\
\text { You know the location of the nearest ticket vending } \\
\text { machine (TVM) which is a walkable distance } \\
\text { from your home. } \\
\text { Go to the nearest TVM. } \\
\text { 1) Order your regular monthly ticket: } \\
\text { a) choose your departure and arrival station and } \\
\text { b) select the regular monthly ticket type. } \\
\text { 2) Pay with your CPC: } \\
\text { a) insert your CPC into ticket vending machine and } \\
\text { b) enter the CPC PIN. } \\
\text { 3) Load the ticket on your transport card: } \\
\text { a) hold your transport card in close to the } \\
\text { contactless communication point and wait } \\
\text { for completion. } \\
\text { 4) Take the purchase invoice (paper form) } \\
\text { printed by the ticket vending machine. }\end{array}$ & \multicolumn{2}{|c|}{$\begin{array}{l}\text { You have a CPC and high speed internet access at home. } \\
\text { Your CPC is accepted by your local transport network } \\
\text { as a ticket. You are aware that you will have to use } \\
\text { the same CPC to check-in and check-out. } \\
\text { Open the internet browser on your home computer } \\
\text { and go to the transport network website. } \\
\text { 1) Order your regular monthly ticket online: } \\
\text { a) choose your departure and arrival station; } \\
\text { b) select the regular monthly ticket type; } \\
\text { c) enter your name and surname; } \\
\text { d) select CPC type and } \\
\text { e) enter CPC number. } \\
\text { 2) Pay with your CPC: } \\
\text { a) enter CPC expiration date and security code. } \\
\text { 3) Download the purchase invoice (pdf file) } \\
\text { and save it on your computer. }\end{array}$} \\
\hline & \multicolumn{3}{|c|}{ To complete the described procedure for ordering, paying and obtaining a new ticket you will need: } \\
\hline & $\begin{array}{lr}1 & \text { very little concentration; negligible an } \\
2 & \text { very little concentration; considerable an } \\
3 & \text { moderate concentration; negligible an } \\
4 & \text { moderate concentration; considerable an } \\
5 & \text { extensive concentration: regardless }\end{array}$ & $\begin{array}{l}\text { nt of time and trivial physical activity } \\
\text { nt of time or non-trivial physical activity } \\
\text { nt of time and trivial physical activity } \\
\text { nt of time or non-trivial physical activity } \\
\text { required time and phvsical activity }\end{array}$ & $\begin{array}{l}1 \\
2 \\
3 \\
4 \\
5\end{array}$ \\
\hline
\end{tabular}

Figure 3. Scoring the convenience factors - sample touch point from questionnaire

Two scenarios were selected to compose the questionnaire in the survey: one for the long-distance regular passengers using season tickets and one for the shortdistance occasional passengers using stored-value tickets. It was assumed that passengers have a credit, debit or prepaid contactless payment card and high-speed fixed internet. Scenarios were then tailored first to the traditional ticketing system and second to the CPC ticketing system. Both scenarios were treated equally. This means that the evaluated ticketing convenience of two ticketing technologies is fixed to the predefined structure of passengers (half regular, half occasional).

The Delphi method was also used for the scoring of the convenience. It was carried out in the same way and by the same 18 members of the expert group as for the ranking of the convenience factors.

Although the developed methodological framework for evaluating ticketing technology is general, the survey was limited to ungated ticketing systems with onboard check-in and check-out validation.

\section{Results}

The key results of the survey are a ticketing convenience model and a quantitative comparison of ticketing convenience for CPC and traditional ticketing systems.

\subsection{The ticketing convenience model}

Survey results of ranking and converting them into weights give us the convenience factors shown in Figure 4.

The survey shows that the most important ticketing convenience factor is general information about the ticketing media, ticket types (features) and prices, which is accessible through the information phase. The second most important ticketing convenience factor is the way the ticketing media is ordered, paid for and delivered,

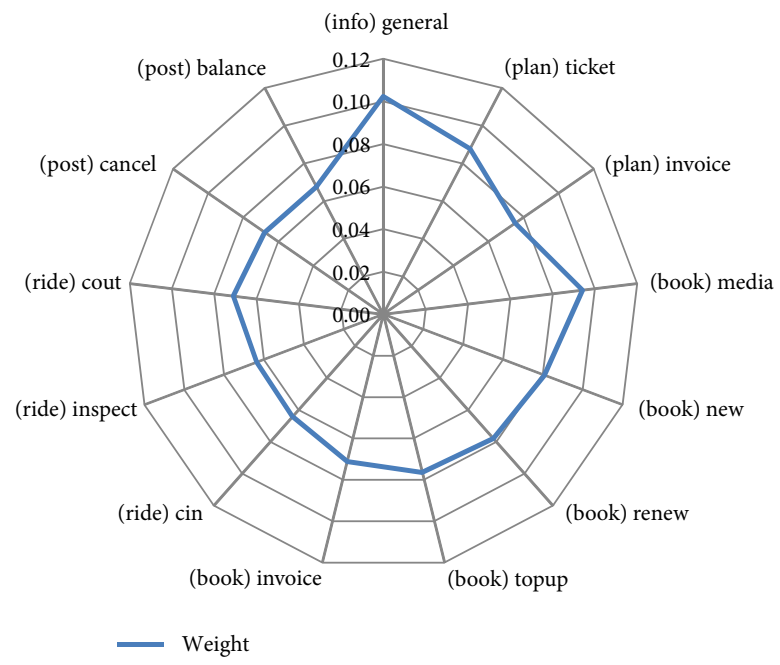

Figure 4. The importance (weight) of ticketing convenience factors

which is implemented in the booking phase. Therefore, the most important questions are whether a passenger needs ticketing media before travel, what ticket types are available, what the price for the ride is, how to obtain ticketing media, and which payment methods are possible.

We use convenience factors to get the ticketing convenience model for ungated, double-ended validation ticketing systems:

$$
\begin{aligned}
& c_{x u d}=0.1022 \cdot c_{x(\text { info })(\text { general })}+ \\
& 0.0878 \cdot c_{x(\text { plan })(\text { ticket })}+0.0752 \cdot c_{x(\text { plan })(\text { invoice })}+ \\
& 0.0942 \cdot c_{x(\text { book })(\text { media })}+0.0809 \cdot c_{x(\text { book })(\text { new })}+ \\
& 0.0779 \cdot c_{x(\text { book })(\text { renew })}+0.0764 \cdot c_{x(\text { book })(\text { topup })}+
\end{aligned}
$$




$$
\begin{aligned}
& 0.0712 \cdot c_{x(\text { book })(\text { invoice })}+0.0643 \cdot c_{x(\text { ride }))(\text { cin })}{ }^{+} \\
& 0.0636 \cdot c_{x(\text { ride })(\text { inspect })}+0.0710 \cdot c_{x(\text { ride })(\text { cout })}{ }^{+} \\
& 0.0677 \cdot c_{x(\text { post })(\text { cancel })}+0.0677 \cdot c_{x(\text { post })(\text { balance })} .
\end{aligned}
$$

We use the model in the survey for CPC and traditional ticketing systems, but it can be used for mobile ticketing and other technologies in future surveys.

\subsection{The quantitative comparison of ticketing convenience}

The survey results of the evaluation of traditional ticketing technology and CPC ticketing technology confirm our hypothesis that CPC ticketing systems are more convenient than traditional ticketing systems (at least for ungated, check-in/check-out validation with baseline functionality). The evaluation shows that the overall normalised convenience for traditional ticketing technology is $c_{\text {tud }}=0.58$ and for CPC ticketing technology is $c_{c u d}=0.70$. Both technologies were evaluated based on an ungated system, with double-side (check-in and check-out) validation and baseline functionality (multiple, season and stored-value ticket types). The CPC ticketing system has $20 \%$ better overall convenience than the traditional ticketing system.

The detailed comparison between traditional and CPC ticketing systems regarding individual convenience factors is presented in radar chart form in Figure 5. The comparison shows better passenger experiences for CPC ticketing in all journey phases except the in-ride phase. The most important differences are within the booking phase: ordering, paying for and delivering the ticketing media, as well as the top-up methods. There is no need for ordering, paying for and delivering the ticketing media for CPC systems because the passenger already has the ticketing media - their contactless payment card. In addition, there is no need to top-up credit or debit contactless cards, because the money is drawn from the bank account. The planning phase is a little surprising, because there is almost no difference between CPC and traditional systems.

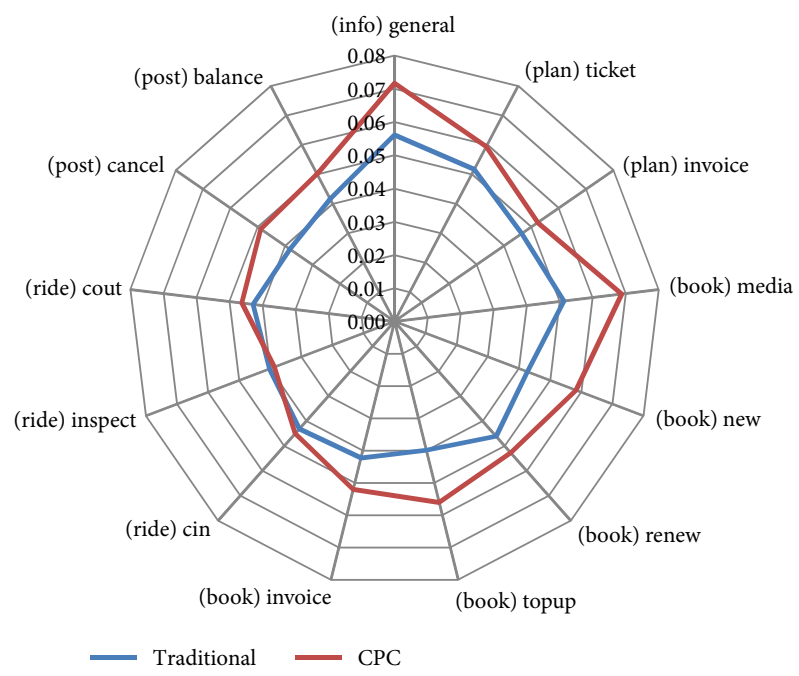

Figure 5. Comparison between traditional and CPC ticketing convenience factors

\subsection{The qualitative comparison of ticketing convenience}

In order to get a quick, and at least minimal, verification of the ticketing convenience model, the simple method for qualitative comparison of ticketing convenience between two ticketing systems was used. The qualitative comparison between traditional and CPC ticketing systems based on the identified convenience factors in Table 2 is presented in Table 3 separately for PayG and PayB functionality.

For the qualitative comparison of the ticketing systems, the relative convenience for each touch point was assessed as lesser convenience $(<)$, equal or approximately equal convenience $(=, \approx)$, or greater convenience $(>)$. It was assumed by the authors that a touch point where no interaction is necessary has greater convenience then a touch point where some interaction is necessary. In addition, a touch point where simple, straightforward or no information is necessary has greater convenience than a touch point where complex or complicated information is necessary. When all convenience factors have greater or equal relative convenience then overall convenience is greater or the same.

Table 3 also shows the conformance between the quantitative and qualitative comparison of ticketing convenience between two ticketing systems, which confirms the correctness of the methodological framework. While the qualitative comparison shows only lesser, equal or greater convenience, the quantitative comparison shows the ratio of convenience factors between two ticketing systems.

\section{Discussion and conclusions}

This study presents a methodological framework for modelling public transport ticketing convenience based on the end-to-end passenger experience, which is expressed as a number of interactions between the passenger and the ticketing system. The study shows that the concept of customer experience can be translated to the concept of ticketing convenience.

The results of the study are a ticketing convenience model and an evaluation of convenience for traditional smart ticketing and smart ticketing based on contactless payment cards. This model, when used with the same convenience factors, can also be used with other technologies (e.g. mobile ticketing). The results of the evaluation show that CPC ticketing technology has greater convenience or provides a better, more seamless travel experience than traditional smart ticketing technology which also means it has a higher potential to increase ridership.

There are several noteworthy limitations of this study. Firstly, the ticketing convenience model is limited because the survey is based on an ungated network (barrier free) with double-ended validation (check-in and check-out validation). This means that the resulting ticketing convenience model cannot be used for a gated network, nor for single-ended validation regardless of whether the methodological framework is general. 
Table 3. The qualitative comparison of ticketing convenience

\begin{tabular}{|c|c|c|c|c|c|c|}
\hline \multirow{2}{*}{\multicolumn{2}{|c|}{ Journey phase }} & \multirow{3}{*}{$\begin{array}{l}\text { Convenience factors } \\
\text { ticketing media, ticket types (features) and price information } \\
\text { (interaction with passenger information system) }\end{array}$} & \multicolumn{4}{|c|}{$\begin{array}{l}\text { Relative passenger experience } \\
\text { (CPC/traditional) }\end{array}$} \\
\hline & & & \multicolumn{2}{|c|}{ PayG } & \multicolumn{2}{|c|}{ PayB } \\
\hline & $\begin{array}{l}\text { information } \\
\text { phase }\end{array}$ & & $>$ & 1.16 & $>$ & 1.39 \\
\hline \multirow{2}{*}{ \$ } & \multirow{2}{*}{$\begin{array}{l}\text { planning } \\
\text { phase }\end{array}$} & ticket type selection & $=$ & 1.25 & $=$ & 1.06 \\
\hline & & $\begin{array}{l}\text { proforma invoice delivery (interaction with journey planner - } \\
\text { passenger information system) }\end{array}$ & $>$ & 1.25 & $=$ & 1.00 \\
\hline & \multirow{5}{*}{$\begin{array}{l}\text { booking } \\
\text { phase }\end{array}$} & ticketing media order, payment and delivery & $>$ & 1.22 & $>$ & 1.46 \\
\hline & & $\begin{array}{l}\text { new ticket order (seat reservation), payment and delivery } \\
\text { (interaction with booking and payment system) }\end{array}$ & l & l & $>$ & 1.37 \\
\hline & & $\begin{array}{l}\text { ticket renewal order, payment and delivery (interaction } \\
\text { with payment system) }\end{array}$ & l & l & $>$ & 1.14 \\
\hline & & $\begin{array}{l}\text { ticket top-up order, payment and delivery (interaction } \\
\text { with payment system) }\end{array}$ & $>$ & 1.40 & / & l \\
\hline & & invoice - receipt delivery & $\approx$ & 1.17 & $\approx$ & 1.29 \\
\hline & $\begin{array}{l}\text { pre-ride } \\
\text { phase }\end{array}$ & ticket validation at enter (at gates) & $=$ & - & $=$ & - \\
\hline \multirow{3}{*}{ إمبحن } & \multirow{3}{*}{$\begin{array}{l}\text { in-ride } \\
\text { phase }\end{array}$} & ticket validation at enter (on board) & $=$ & 1.06 & $=$ & 1.03 \\
\hline & & ticket and identity inspection & $=$ & 0.95 & $=$ & 0.97 \\
\hline & & ticket validation at exit (on board) & $=$ & 1.05 & $=$ & 1.11 \\
\hline \multirow{3}{*}{$\dot{\hat{K}} \rightarrow$} & \multirow{3}{*}{$\begin{array}{l}\text { post-ride } \\
\text { phase }\end{array}$} & ticket validation at exit (at gates) & $=$ & - & $=$ & - \\
\hline & & return and refund media, refund unused or cancelled tickets & / & l & $>$ & 1.28 \\
\hline & & return and refund media, refund unused stored value & $>$ & 1.20 & I & l \\
\hline & & end-to-end passenger experience & $>$ & & $>$ & \\
\hline
\end{tabular}

Secondly, the measurement of ticketing convenience is limited to two different scenarios of using public transport. Thirdly, the evaluation and thus the comparison of ticketing technologies are limited to predefined baseline ticketing system functionality. Fourthly, the study is based on a single survey carried out with a local expert group.

This methodological framework for measuring the convenience of transport ticketing based on the customer experience concept fills the gap in the literature in the research field of transport ticketing. The methodological framework developed here may have practical implications for the process of selecting technology and functionality during an introduction, upgrade or replacement of a ticketing system (and ticketing-related systems such as passenger information and booking systems) and for the advanced ridership forecasting methods which contain convenience as an unobservable attribute (hybrid discrete choice modelling).

In the methodological framework, simple methods for determining the overall convenience of the ticketing system were used. The objective of future research could be the appropriateness of different, more sophisticated methods. Special attention should be devoted to methods, which take into account missing values (missing touch points) for some criteria, so that a greater degree of generalisation of convenience models is possible. Ide- ally, the same convenience model would be usable for gated and ungated, and single- or double-ended validation systems.

Two equally treated scenarios of using public transport were applied in the survey: the PayG scenario for regular passengers and the PayB scenario for the occasional passengers. To estimate ticketing convenience, different assumptions regarding different categories of passengers (banked versus unbanked or underbanked, regular or occasional, ordinary or subsidised, domestic or foreign, business travellers or tourists) can be made. Future research could analyse the impact of the larger set of scenarios with a sensitivity analysis of the different treatment of scenarios.

The initial methodological framework for measuring the convenience of transport ticketing is based on complex interactions between the passenger and the public transport operator's transport ticketing system, which can be further decomposed into simpler touch points. A detailed breakdown of interactions leads to a separation of touch points into those related to ticketing systems and those related to associated systems such as passenger information systems, booking systems and payment systems. Besides transport ticketing, booking, payment and passenger information (static and realtime) systems, there are some other technologies such as indoor and outdoor navigation (static and real-time) 
which have also an important role in creating the passenger experience. Smart mobile phones with built-in NFC technology are new devices which promise to act as a digital wallet in which various smart cards for transport, payments, loyalty, identity and other purposes can be inserted. Smart mobile phones are able to plan the journey, visualise and deliver the ticket over the air (over the mobile network or Wi-Fi). Many of them have built-in BLE and GPS technology, which can be used for indoor and outdoor navigation. Mobile ticketing is definitively one of the important future directions of transport ticketing. Future research could analyse the ticketing convenience for such advanced mobile ticketing.

\section{References}

Anderson, R.; Condry, B.; Findlay, N.; Brage-Ardao, R.; Li, H. 2013. Measuring and valuing convenience and service quality: a review of global practices and challenges from mass transit operators and railway industries, International Transport Forum Discussion Papers 16: 1-47. https://doi.org/10.1787/5k3z04gb6zs1-en

Annema, J. A. 2013. Transport resistance factors: time, money and effort, in B. Van Wee, J. A. Annema, D. Banister (Eds.). The Transport System and Transport Policy: an Introduction, 101-124.

Ben-Akiva, M.; Walker, J.; Bernardino, A. T.; Gopinath, D. A.; Morikawa, T.; Polydoropoulou, A. 1999. Integration of Choice and Latent Variable Models. Massachusetts Institute of Technology. US. $40 \mathrm{p}$.

Berry, L. L.; Seiders, K.; Grewal, D. 2002. Understanding service convenience, Journal of Marketing 66(3): 1-17. https://doi.org/10.1509/jmkg.66.3.1.18505

Bevan, N.; Carter, J.; Harker, S. 2015. ISO 9241-11 revised: what have we learnt about usability since 1998?, Lecture Notes in Computer Science 9169: 143-151. https://doi.org/10.1007/978-3-319-20901-2_13

Brakewood, C. 2010. Contactless Prepaid and Bankcards in Transit Fare Collection Systems: MSc Thesis. Massachusetts Institute of Technology, US. 122 p. Available from Internet: https://dspace.mit.edu/handle/1721.1/60796

Brakewood, C.; Kocur, G. 2011. Modeling transit rider preferences for contactless bank cards as fare media: transport for London and the Chicago, Illinois, transit authority, Transportation Research Record: Journal of the Transportation Research Board 2216: 100-107. https://doi.org/10.3141/2216-11

Brakewood, C.; Rojas, F.; Robin, J.; Sion, J.; Jordan, S. 2014. Forecasting mobile ticketing adoption on commuter rail, Journal of Public Transportation 17(1): 1-19. https://doi.org/10.5038/2375-0901.17.1.1

Buehler, R.; Pucher, J. 2012. Demand for public transport in Germany and the USA: an analysis of rider characteristics, Transport Reviews 32(5): 541-567. https://doi.org/10.1080/01441647.2012.707695

Crockett, J.; Hounsell, N. 2005. Role of the travel factor convenience in rail travel and a framework for its assessment, Transport Reviews 25(5): 535-555. https://doi.org/10.1080/01441640500064389

Davis, F. D. 1989. Perceived usefulness, perceived ease of use, and user acceptance of information technology, MIS Quarterly 13(3): 319-340. https://doi.org/10.2307/249008
Farquhar, J. D.; Rowley, J. 2009. Convenience: a services perspective, Marketing Theory 9(4): 425-438.

https://doi.org/10.1177/1470593109346894

Ferreira, H.; Teixeira, A. A. C. 2013. Welcome to the experience economy: assessing the influence of customer experience literature through bibliometric analysis, FEP Working Papers 481: 1-29.

Graham, P.; Mulley, C. 2012. Public transport pre-pay tickets: Understanding passenger choice for different products, Transport Policy 19(1): 69-75. http://doi.org/10.1016/j.tranpol.2011.07.003

Hsu, C.-C.; Sandford, B. A. 2007. The Delphi technique: making sense of consensus, Practical Assessment, Research \& Evaluation 12(10): 1-8.

ISO 9241-11:1998. Ergonomic Requirements for Office Work with Visual Display Terminals (VDTs). Part 11: Guidance on Usability.

Johnston, R.; Kong, X. 2011. The customer experience: a roadmap for improvement, Managing Service Quality: an International Journal 21(1): 5-24.

https://doi.org/10.1108/09604521111100225

Joppien, J. 2013. Improving System Adoption of the OV-Chipkaart: MSc Thesis. Delft University of Technology. Netherlands. 176 p. Available from Internet: http://studiolab. ide.tudelft.nl/studiolab/ovchipkaart/files/2014/06/OVCPTUD-System-Adoption-Joppien.pdf

Joppien, J.; Niermeijer, G.; Niks, M. C.; Van Kuijk, J. I. 2013. Exploring New Possibilities for User-Centred E-Ticketing. Analysis Report. Delft University of Technology, Netherlands. 208 p.

Mallat, N.; Rossi, M.; Tuunainen, V. K.; Öörni, A. 2008. An empirical investigation of mobile ticketing service adoption in public transportation, Personal and Ubiquitous Computing 12(1): 57-65. https://doi.org/10.1007/s00779-006-0126-z

Nielsen, J. 1993. Usability Engineering. Morgan Kaufmann. $362 \mathrm{p}$.

Oxford English Dictionary. 2016. Available from Internet: http://www.oed.com

Pine, B. J.; Gilmore, J. H. 1998. Welcome to the experience economy, Harvard Business Review 76(4): 97-105.

Puhe, M.; Edelmann, M.; Reichenbach, M. 2014. Integrated Urban E-Ticketing for Public Transport and Touristic Sites. Final Report on Application Concepts and the Role of Involved Stakeholders. European Parliamentary Research Service. 96 p.

Rogers, E. M. 1995. Diffusion of Innovations. 4th edition. Free Press. 518 p.

Smart Card Alliance. 2008. Serving Unbanked Consumers in the Transit Industry with Prepaid Cards. A Smart Card Alliance Transportation Council White Paper. Publication No TC-08002. New Jersey, US. 31 p. Available from Internet: http://www.smartcardalliance.org/resources/lib/Serving_Unbanked_Transit_Riders_White_Paper.pdf

Smart Card Alliance. 2011. A Guide to Prepaid Cards for Transit Agencies. A Smart Card Alliance Transportation Council White Paper. Publication No TC-11001. New Jersey, US. 38 p. Available from Internet: http://www.smartcardalliance.org/resources/pdf/Prepaid_Cards_for_Transit_Agencies_20110212.pdf

The UK Cards Association Ltd. 2015. Contactless Transit. Available from Internet: http://www.theukcardsassociation. org.uk/contactless_transport/index.asp 
Tirachini, A. 2013. Estimation of travel time and the benefits of upgrading the fare payment technology in urban bus services, Transportation Research Part C: Emerging Technologies 30: 239-256. https://doi.org/10.1016/j.trc.2011.11.007

TfL. 2016. Card Clash. Transport for London (TfL), UK. Available from Internet: https://tfl.gov.uk/fares-and-payments/ oyster/using-oyster/card-clash

Triantaphyllou, E.; Shu, B.; Nieto Sanchez, S.; Ray, T. 1998. Multi-criteria decision making: an operations research approach, in J. G. Webster (Ed.). Encyclopedia of Electrical and Electronics Engineering 15: 175-186.

Turner, M.; Wilson, R. 2010. Smart and integrated ticketing in the UK: Piecing together the jigsaw, Computer Law \& Security Review 26(2): 170-177. https://doi.org/10.1016/j.clsr.2010.01.015

Velasquez, M.; Hester, P. T. 2013. An analysis of multi-criteria decision making methods, International Journal of Operations Research 10(2): 56-66.

Venkatesh, V.; Bala, H. 2008. Technology acceptance model 3 and a research agenda on interventions, Decision Sciences 39(2): 273-315. https://doi.org/10.1111/j.1540-5915.2008.00192.x

Zardari, N. H.; Ahmed, K.; Shirazi, S. M.; Yusop, Z. B. 2015. Weighting Methods and their Effects on Multi-Criteria Decision Making Model Outcomes in Water Resources Management. Springer. $166 \mathrm{p}$.

https://doi.org/10.1007/978-3-319-12586-2 